\section{Cureus}

Received 03/25/2014

Review began 03/26/2014

Review ended 04/17/2014

Published 04/18/2014

C) Copyright 2014

Jusué-Torres et al. This is an open access article distributed under the terms of the Creative Commons Attribution License CC-BY 3.0., which permits unrestricted use, distribution, and reproduction in any medium, provided the original author and source are credited.

\title{
Complications of Lumboperitoneal Shunts for Normal Pressure Hydrocephalus
}

\author{
Ignacio Jusué-Torres $^{1}$, Jamie B. Hoffberger ${ }^{2}$, Daniele Rigamonti ${ }^{2}$ \\ 1. Department of Neurosurgery, Loyola University Chicago, Stritch School of Medicine, Maywood, Illinois \\ 2. Department of Neurosurgery, The Johns Hopkins University School of Medicine
}

$\square$ Corresponding author: Ignacio Jusué-Torres, ignaciojusue@gmail.com

Disclosures can be found in Additional Information at the end of the article

\section{Abstract}

For the past half century, the mainstay of cerebrospinal fluid shunting for normal pressure hydrocephalus (NPH) has been ventriculoperitoneal shunt surgery. Lumboperitoneal (LP) shunt has been used occasionally and seemed to be associated with higher failure rates compared to ventriculoperitoneal shunts. There is no uniformity in the reporting of complication and surgical revision rates.

Goals of this study were to understand better the complications and the causes of surgical revisions post-LP shunt insertion in NPH patients.

Nine patients with NPH undergoing lumboperitoneal shunt surgery for the first time by the senior author at an academy tertiary-care institution were retrospectively reviewed. Presence of complications and surgical revisions were the two main outcome variables. Logistic regression analysis was used first to assess if there was a correlation between preoperative patient characteristics and complications and second to evaluate if there was any association between postsurgical complications and surgical revision.

Primary shunts were inserted into nine patients and 44\% required revision surgery. Median time to surgical revision was nine (two to 16) months. Multivariate logistic analysis showed no statistical significant association between preoperative patient characteristics and postoperative complications as well as no relationship between preoperative characteristics or complications and surgical revisions.

While minimizing risks of intracranial complications, high rates of postoperative complications as well as the frequent need for multiple shunt revisions are significant disadvantages for lumboperitoneal shunt in NPH. Our Japanese colleagues ascribe lower complication rates to an overall lower BMI. Prospective studies with stronger statistical power are needed to clarify this question.

Categories: Neurology, Neurosurgery

Keywords: complication, normal pressure hydrocephalus, follow-up, lumboperitoneal shunt, postoperative morbidity, reoperation, surgical revision

\section{Introduction}

For the past half century, the mainstay of treatment for normal pressure hydrocephalus (NPH) has been ventriculoperitoneal shunt surgery [1-4]. However, in Japan, normal pressure hydrocephalus is not infrequently managed with lumboperitoneal (LP) shunt surgery [5]. In 
some institutions, the LP shunt comprises up to $40 \%$ of all CSF shunting procedures [6]. The main reason LP shunt is considered when treating patients with NPH is the avoidance of the risk of intracranial hemorrhage while passing a catheter through the brain parenchyma. Nevertheless, the LP shunt has been associated with higher failure rates compared to ventriculoperitoneal shunts [3-4, 7-13]. However, the literature is characterized by lack of uniformity in reporting complication and surgical revision rates after LP shunting [4, 13-15]. Difference in the size of previous cohort studies as well as the tendency to under-report poor outcomes may at least in part explain this finding [3, 16-32]. We conducted the present study with the intention to understand better the complications and causes of surgical revisions following LP shunt insertion in NPH patients.

\section{Materials And Methods}

Institutional Review Board (IRB) approval (\#44584) was obtained prior to the start of this study

All adult patients (age > 18) that received primary placement of LP shunt with horizontalvertical $(\mathrm{H}-\mathrm{V})$ lumbar valve systems as treatment of NPH by the senior author were included. Exclusion criteria comprised: conditions other than NPH treated with LP shunts, non-primaryplaced LP shunts, and pediatric patients.

From 1994 to 2013, there were a total of 41 adult patients who underwent lumboperitoneal shunt surgery for the first time by the senior author at a single academic tertiary-care institution. Patients $(n=32)$ with idiopathic intracranial hypertension, Crouzon, preoperative CSF leak, multiple sclerosis, and syringomyelia were excluded. In total, nine patients met the inclusion criteria.

The clinical records of the included patients were retrospectively reviewed. The information collected from clinical notes included: demographics, body mass index (BMI), presenting symptoms (gait problems, incontinence, cognitive impairment), etiology (hemorrhagic, infectious, traumatic), opening pressure in $\mathrm{mmHg}$, follow-up time in months, and valve characteristics.

The two main outcomes included presence of complications and surgical revisions. Data was collected on the number of surgical revisions per patient, time to revision in months, conversion to other type of shunt, reprogramming, and if there was a change in the type of valve. Missing data was documented.

Summary data is presented as frequencies and percentage for categorical variables and median and interquartile range (IQR) for continuous variables. Logistic regression analysis was used to assess if there was a correlation between preoperative patient characteristics and complications. This same analysis was used to evaluate if there was any association between preoperative patient characteristics or postsurgical complications and surgical revision. Statistically significant differences were considered when $\mathrm{p}<0.05$.

Overall, time required for surgical revision was plotted using the Kaplan-Meier method ( $\mathrm{R}$ statistic software (version 3.0.1)) [33].

\section{Results}

Nine patients with NPH underwent lumboperitoneal shunting over the 20-year study period. Patient characteristics are shown in Table 1. 


\section{Cureus}

\begin{tabular}{|c|c|}
\hline & $\mathrm{NPH} n=9(\%)$ \\
\hline Age (years) & $76(69-78)$ \\
\hline Female: Male & 4/5 (0.8:1) \\
\hline White & $6(67 \%)$ \\
\hline Atrican-American & $0(0 \%)$ \\
\hline BMI & $28(25-31)$ \\
\hline Obesity & $2(22 \%)$ \\
\hline Morbid Obesity & $0(0 \%)$ \\
\hline Gait and balance problems & $8(89 \%)$ \\
\hline Incontinence & $7(78 \%)$ \\
\hline Cognitive impairment & $6(67 \%)$ \\
\hline Optic neuropathy & $1(11 \%)$ \\
\hline Papilledema & $0(0 \%)$ \\
\hline \multicolumn{2}{|l|}{ Etiology } \\
\hline Unknown & $7(78 \%)$ \\
\hline Hemorrhagic & $1(11 \%)$ \\
\hline Infectious & $7(11 \%)$ \\
\hline Traumatic & $0(0 \%)$ \\
\hline Previously shunted & $3(33 \%)$ \\
\hline Opening pressure $\left(\mathrm{mm} \mathrm{H}_{2} \mathrm{O}\right)$ & $286(272-375)$ \\
\hline Follow up time (years) & $3(2-6)$ \\
\hline
\end{tabular}

\section{TABLE 1: Patient characteristics}

Median follow-up (IQR) was three (two to six) years. Median age (IQR) was 76 (69-78) years old. Female/male ratio was 0.8:1, and median body mass index (IQR) 28 (25-31) with a $22 \%$ rate of obese patients. The most common presenting symptoms included gait and balance problems (89\%), incontinence (78\%), and cognitive impairment (67\%). Median opening pressure (IQR) was $286(272-375) \mathrm{mm} \mathrm{H}_{2} \mathrm{O}$.

We found that four patients (44\%) developed at least one complication. Complication characteristics are shown in Figure 1 and Table 2. 


\section{Cureus}
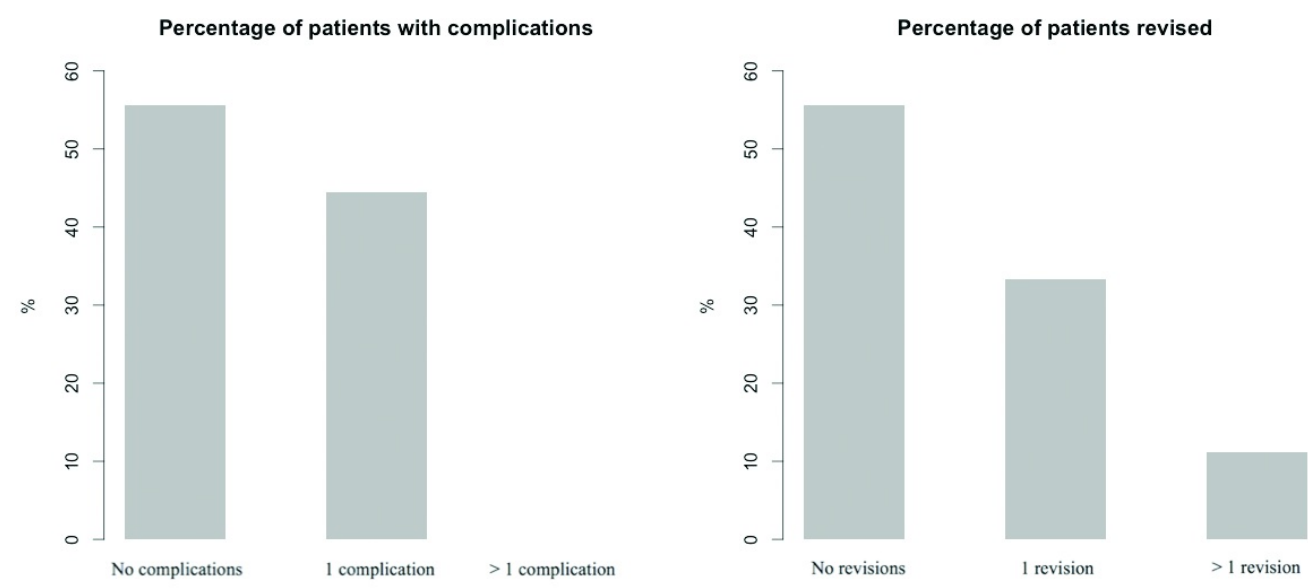

FIGURE 1: Barplots showing: A. Percentage of LP shunt patients with no complications, one complication, or more than one complication.

B. Percentage of LP shunt patients with no surgical revisions, one surgical revision, or more than one surgical revision.

\begin{tabular}{ll}
\hline Obstruction & NPH n=9 (\%) \\
Infection & $1(11 \%)$ \\
Hearing loss & $1(11 \%)$ \\
Pseudomeningocele & $1(11 \%)$ \\
Overdrainage & $1(11 \%)$ \\
Mechanical failure & $0(0 \%)$ \\
CSF leak & $0(0 \%)$ \\
Abdominal pain & $0(0 \%)$ \\
Wound dehiscence & $0(0 \%)$ \\
Tinnitus & $0(0 \%)$ \\
Total \# of patients with complications & $0(0 \%)$ \\
\hline
\end{tabular}

TABLE 2: Lumboperitoneal shunt related complications in NPH patients. 


\section{Cureus}

placement in our patients, such as seizure, pneumocephalus, subdural collection, venous sinus thrombosis, catheter malposition, ileus, gastrointestinal perforation, abdominal hemorrhage, myelopathy, syringomyelia, scoliosis, lumbar hyperlordosis, tonsillar herniation or acquired Chiari I malformation, preterm delivery in pregnancy, spontaneous abortion in pregnancy, and hydrocele.

Furthermore, four patients (44\%) required revision surgery, detailed in Figure 2 and Table 3.
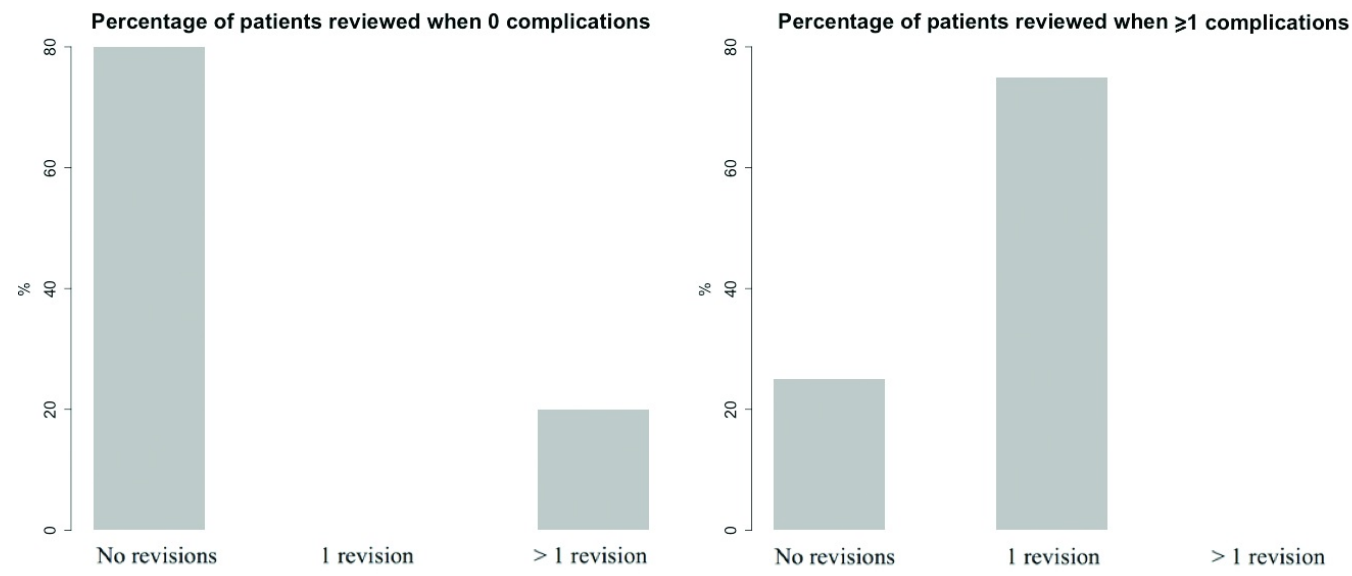

\section{FIGURE 2: Barplots showing: A. Percentage of LP shunt patients with no complications that get no surgical revisions, one surgical revision, or more than one surgical revision.}

B. Percentage of LP shunt patients with one or more complications that get no surgical revisions, one surgical revision, or more than one surgical revision.

Num. of patients surgically revised

Patients that required multiple revisions

Time to revision (months)

Conversion to other type of shunt

Change of type of valve

Reprogramming
NPH $n=9(\%)$

$4(44 \%)$

$1(11 \%)$

$9(2-16)$

$2(22 \%)$

$0(0 \%)$

$0(0 \%)$

\section{TABLE 3: Surgical revisions of lumboperitoneal shunt in NPH patients}

Among subjects requiring a shunt revision, three (75\%) had one revision, while one (25\%) required multiple revisions. Primary shunts were therefore inserted into nine patients, and five revision surgeries were required. Median time to surgical revision was nine (two to 16) months. 


\section{Cureus}

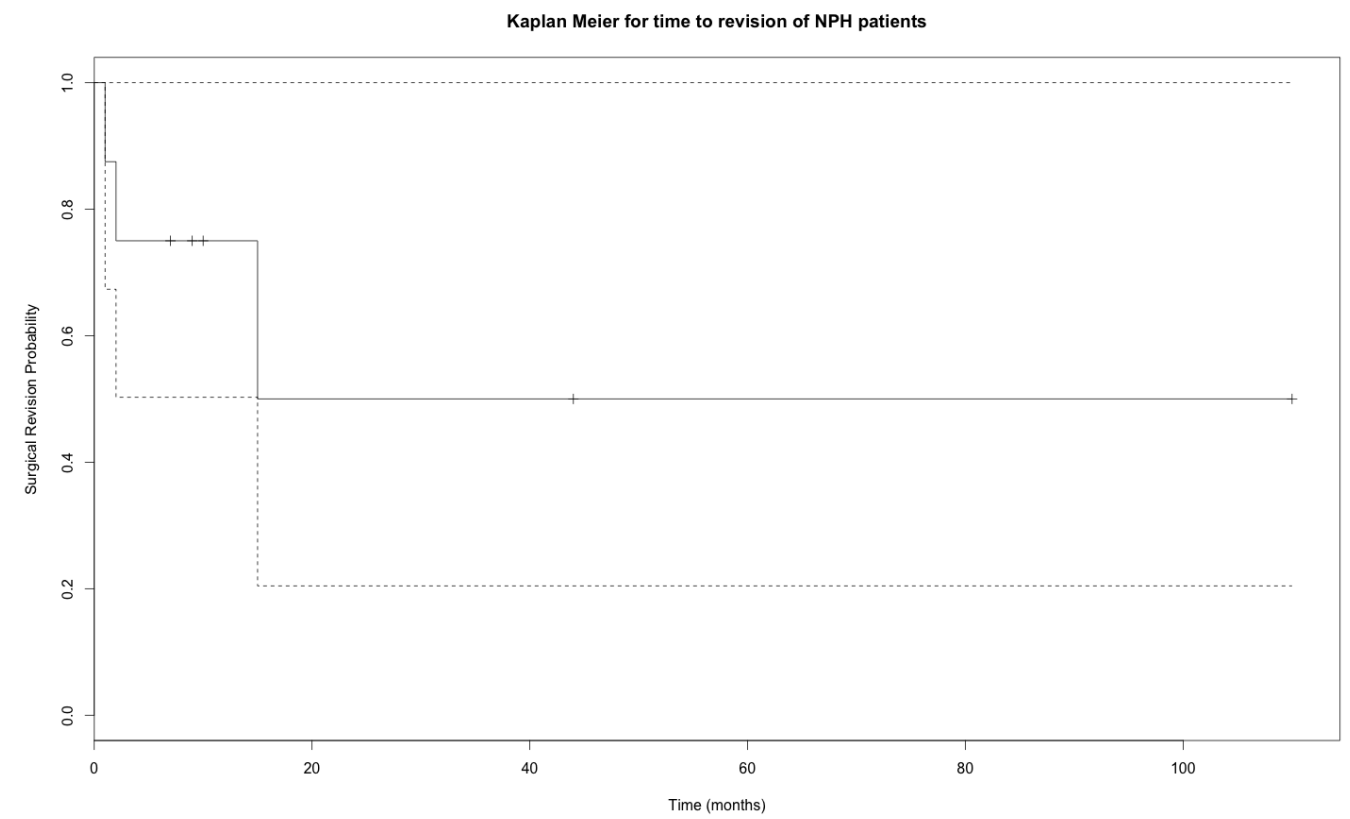

FIGURE 3: Kaplan Meier curves of time to surgical revision

Half of the revisions occurred within the first three months after surgery.

Univariate and multivariate logistic regression did not show any correlation between any of the preoperative factors and the risk of post-LPS complication. Likewise, we did not find any correlation between preoperative factors and risk of surgical revision.

\section{Discussion}

Lumboperitoneal shunting is considered in the treatment of NPH in order to minimize the intracranial risks associated with ventricular shunting systems [13, 34-36]. However, since the early days of shunt insertion, shunt complications have been considered a serious problem $[2$, $27,37]$. During the initial attempts of this technique, there was a very high perioperative mortality [10,16]. Substitution of polyethylene catheters by Silastic catheters in 1967 lead to a dramatic decline in obstruction and shunt fracture rate [38]. However, complication and surgical revision rates for LP shunting have continued to be reported in the literature [4, 13-15]. Of note, the LP shunt has been associated with higher failure rates compared to ventriculoperitoneal shunts $[3,7-9,11]$. As a consequence of this, ventriculoperitoneal shunts have been the prevalent treatment modality for NPH. The lack of clear data regarding the complication and revision rates of LP shunts in NPH may perpetuate this situation [5-6]. Our data suggests that some of the previously reported complications (seizure, pneumoencephalus, subdural collection, venous sinus thrombosis, catheter malposition, ileus, gastrointestinal perforation, abdominal hemorrhage, myelopathy, syringomyelia, scoliosis, lumbar hyperlordosis, tonsillar herniation or acquired Chiari I malformation, preterm delivery in pregnancy, spontaneous abortion in pregnancy, and hydrocele) are no longer occurring. However, mechanical complications of lumboperitoneal shunts seem to remain high. Nevertheless, hearing impairment may be due to overdrainage and can be addressed with an increment in the valve pressure setting [17].

Japanese authors explain their lower complication and revision rates by lower BMI [6]. In our experience, obstruction and mechanical complication rates were lower than previously 
reported. That could be explained by the fact that our cohort had a median BMI (IQR) of 28 [2531]. Unfortunately, we did not find any correlation between BMI and the complication rates or surgical revision rates. This could be due to the fact of weak statistical power because of a small cohort. Thus, it is not clear if the Japanese theory may be supported by our data.

We acknowledge limitations of our study that may influence our results and that may reduce the generalizability or extrapolation of its conclusions to patients from other centers. Our study was not controlled or prospectively designed; it looked at data over a very long period of time; and had a low statistical power due to a small sample. However, this series, being limited to a single surgeon experience, reduced the variability of indication and technique derived from it. Stronger scientific evidence is necessary and requires prospective studies to better assess the current risk and benefits of LP shunting in NPH patients.

\section{Conclusions}

While minimizing risks of intracranial complications, the high rate of postoperative complications as well as the frequent need for multiple shunt revisions are significant disadvantages for lumboperitoneal shunting in NPH. Our Japanese colleagues, reporting lower complication rates, ascribe this fact to an overall lower BMI. Further prospective studies with stronger statistical power are needed to further clarify this question.

\section{Additional Information \\ Disclosures}

Human subjects: All authors have confirmed that this study did not involve human participants or tissue. Animal subjects: All authors have confirmed that this study did not involve animal subjects or tissue. Conflicts of interest: In compliance with the ICMJE uniform disclosure form, all authors declare the following: Payment/services info: All authors have declared that no financial support was received from any organization for the submitted work. Financial relationships: All authors have declared that they have no financial relationships at present or within the previous three years with any organizations that might have an interest in the submitted work. Other relationships: All authors have declared that there are no other relationships or activities that could appear to have influenced the submitted work.

\section{Acknowledgements}

IJT was funded by the Salisbury Hydrocephalus Research Fellowship grant and the Swenson Family Foundation.

\section{References}

1. Adams RD, Fisher CM, Hakim S, Ojemann RG, Sweet WH: Symptomatic occult hydrocephalus with "normal" cerebrospinal-fluid pressure. A treatable syndrome. N Engl J Med. 1965, 273:117-126.

2. Pudenz RH: The surgical treatment of hydrocephalus-an historical review . Surg Neurol. 1981, $15: 15-26$.

3. McGirt MJ, Woodworth G, Thomas G, Miller N, Williams M, Rigamonti D: Cerebrospinal fluid shunt placement for pseudotumor cerebri-associated intractable headache: predictors of treatment response and an analysis of long-term outcomes. J Neurosurg. 2004, 101:627-632.

4. Stein SC, Guo W: Have we made progress in preventing shunt failure? A critical analysis . J Neurosurg Pediatr. 2008, 1:40-47. 10.3171/PED-08/01/040

5. Mori E, Ishikawa M, Kato T, Kazui H, Miyake H, Miyajima M, Nakajima M, Hashimoto M, Kuriyama N, Tokuda T, Ishii K, Kaijima M, Hirata Y, Saito M, Arai H: Guidelines for management of idiopathic normal pressure hydrocephalus: second edition. Neurol Med Chir (Tokyo). 2012, 52:775-809. 
6. Yamashiro S, Hitoshi Y, Yoshida A, Kuratsu J: Historical considerations of the predominance of lumboperitoneal shunt for treatment of adult communicating hydrocephalus in Kumamoto, Japan. Clin Neurol Neurosurg. 2012, 114:1115-6. 10.1016/j.clineuro.2012.02.018

7. Choux M, Genitori L, Lang D, Lena G: Shunt implantation: Reducing the incidence of shunt infection. J Neurosurg. 1992, 77:875-80.

8. Faillace WJ: A no-touch technique protocol to diminish cerebrospinal fluid shunt infection . Surg Neurol. 1995, 43:344-50.

9. Kang S: Efficacy of lumbo-peritoneal versus ventriculo-peritoneal shunting for management of chronic hydrocephalus following aneurysmal subarachnoid haemorrhage. Acta Neurochir (Wien). 2000, 142:45-9.

10. Kestle J, Drake J, Milner R, Sainte-Rose C, Cinalli G, Boop F, Piatt J, Haines S, Schiff S, Cochrane D, Steinbok P, MacNeil N: Long-term follow-up data from the Shunt Design Trial . Pediatr Neurosurg. 2000, 33:230-236.

11. Enger PØ, Svendsen F, Wester K: CSF shunt infections in children: Experiences from a population-based study. Acta Neurochir (Wien). 2003, 145:243-8.

12. Browd SR, Ragel BT, Gottfried ON, Kestle JRW: Failure of cerebrospinal fluid shunts: Part I: Obstruction and mechanical failure. Pediatr Neurol. 2006, 34:83-92.

13. Toma AK, Papadopoulos MC, Stapleton S, Kitchen ND, Watkins LD: Systematic review of the outcome of shunt surgery in idiopathic normal-pressure hydrocephalus. Acta Neurochir (Wien). 2013, 155:1977-80. 10.1007/s00701-013-1835-5

14. Sherman CS, Mark GB, Seema SS: Shunts in normal-pressure hydrocephalus: do we place too many or too few?. J Neurosurg. 2006, 105:815-22.

15. Pujari S, Kharkar S, Metellus P, Shuck J, Williams MA, Rigamonti D: Normal pressure hydrocephalus: Long-term outcome after shunt surgery. J Neurol Neurosurg Psychiatry. 2008, 79:1282-6. 10.1136/jnnp.2007.123620

16. Eisenberg HM, Davidson RI, Shillito J Jr: Lumboperitoneal shunts. Review of 34 cases . J Neurosurg. 1971, 35:427-31.

17. Selman WR, Spetzler RF, Wilson CB, Grollmus JW: Percutaneous lumboperitoneal shunt: Review of 130 cases. Neurosurg. 1980, 6:255-7.

18. McIvor J, Krajbich JI, Hoffman H: Orthopaedic complications of lumboperitoneal shunts. J Pediatr Orthop. 1988, 8:687-9.

19. Philippon J, Duplessis E, Dorwling-Carter D, Horn YE, Cornu P: Lumboperitoneal shunt and normal pressure hydrocephalus in elderly subjects. (Article in French). Rev Neurol (Paris). 1989, 145:776-80.

20. Aoki N: Lumboperitoneal shunt: Clinical applications, complications, and comparison with ventriculoperitoneal shunt. Neurosurg. 1990, 26:998-1004.

21. Brunon J, Motuo-Fotso MJ, Duthel R, Huppert J: Treatment of chronic hydrocephalus in adults by lumboperitoneal shunt. Results and indications apropos of 82 cases. (Article in French). Neurochirurgie. 1991, 37:173-8.

22. Easterbrook PJ, Berlin JA, Gopalan R, Matthews DR: Publication bias in clinical research . Lancet. 1991, 337:867-872.

23. Chumas PD, Kulkarni AV, Drake JM, Hoffman HJ, Humphreys RP, Rutka JT: Lumboperitoneal shunting: A retrospective study in the pediatric population. Neurosurg. 1993, 32:376-83.

24. Duthel R, Nuti C, Motuo-Fotso MJ, Beauchesne P, Brunon J: Complications of lumboperitoneal shunts. A retrospective study of a series of 195 patients (214 procedures). (Article in French). Neurochirurgie. 1996, 42:83-90.

25. Chang CC, Kuwana N, Ito S: Management of patients with normal-pressure hydrocephalus by using lumboperitoneal shunt system with the Codman Hakim programmable valve. Neurosurg Focus. 1999, $7: \mathrm{e} 8$.

26. Kamiryo T, Hamada J, Fuwa I, Ushio Y: Acute subdural hematoma after lumboperitoneal shunt placement in patients with normal pressure hydrocephalus. Neurol Med Chir (Tokyo). 2003, 43:197-200.

27. Karabatsou K, Quigley G, Buxton N, Foy P, Mallucci C: Lumboperitoneal shunts: Are the complications acceptable?. Acta Neurochir (Wien). 2004, 146:1193-7.

28. Yadav YR: Lumboperitoneal shunts: Review of 409 cases . Neurol India. 2004, 52:188-90.

29. Wang VY, Barbaro NM, Lawton MT, Pitts L, Kunwar S, Parsa AT, Gupta N, McDermott MW: Complications of lumboperitoneal shunts. Neurosurgery. 2007, 60:1045-9.

30. Barcia-Mariño C, González-Bonet LG, Salvador-Gozalbo L, Goig-Revert F, Rodríguez-Mena R: 
Lumboperitoneal shunt in an outpatient setting for the treatment of chronic hydrocephalus in adults. A study and follow-up of 30 cases. (Article in Spanish). Revista de neurologia. 2009, 49:300-306.

31. Jia L, Zhao ZX, You C, Liu JG, Huang SQ, He M, Ji PG, Duan J, Zeng YJ, Li GP: Minimallyinvasive treatment of communicating hydrocephalus using a percutaneous lumboperitoneal shunt. J Zhejiang Univ Sci B. 2011, 12:293-7. 10.1631/jzus.B1000248

32. Bloch O, McDermott MW: Lumboperitoneal shunts for the treatment of normal pressure hydrocephalus. J Clin Neurosci. 2012, 19:1107-11. 10.1016/j.jocn.2011.11.019

33. R Core Team: A Language and environment for statistical computing. . (2013). http://www.Rproject.org.

34. Williams MA, Sharkey P, Van Doren D, Thomas G, Rigamonti D: Influence of shunt surgery on healthcare expenditures of elderly fee-for-service Medicare beneficiaries with hydrocephalus. J Neurosurg. 2007, 107:21-8.

35. Jia L, Zhao ZX, You C, Liu JG, Huang SQ, He M, Ji PG, Duan J, Zeng YJ, Li GP: Minimallyinvasive treatment of communicating hydrocephalus using a percutaneous lumboperitoneal shunt. J Zhejiang Univ Sci B. 2011, 12:293-7. 10.1631/jzus.B1000248

36. Stranjalis G, Kalamatianos T, Koutsarnakis C, Loufardaki M, Stavrinou L, Sakas DE: Twelveyear hospital outcomes in patients with idiopathic hydrocephalus. Acta Neurochirurgica Supplement. 2012, 113:115-117. 10.1007/978-3-7091-0923-6_23

37. Stein SC, Guo W: Have we made progress in preventing shunt failure? A critical analysis . J Neurosurg Pediatr. 2008, 1:40-47. 10.3171/PED-08/01/040

38. Jones RFC: Long-term results in various treatments of hydrocephalus . J Neurosurg. 1967, 26:313-5. 